\title{
Para Além do Estado e do Mercado: A Dádiva no Fenômeno dos Sem-Abrigo*
}

João Aldeia

Faculdade de Economia da Universidade de Coimbra, Portugal

Sem dúvida, ela era a pessoa mais fiel a si própria mesmo apesar de - ou precisamente por causa - das suas

diversas metamorfoses e enorme incoerência (Cosey,

Viagem a Itália).

\section{INTRODUÇÃO}

Papel da dádiva nas sociedades modernas ocidentais é demasiadas vezes obscurecido, minimizado e/ou negado. O modelo moderno de sociedade é erigido com base num conjunto de idealizações das quais a substituição do dom pelas prestações estatais e pelas relações mercantis é uma das principais. O resultado disto é uma incapacidade dos estudos sociais observarem o que circula fora dos circuitos oficiais e que, contudo, permanece fundamental para a criação de laços sociais e mesmo para a manutenção do Estado e do mercado. A dádiva não é um fenômeno identificável em espaços-tempo "pré-modernos": é um fato social total presente mesmo nas mais "modernas" sociedades (Godbout e Caillé, 1997; Caillé, 2000; Godbout, 2000; Portugal, 2006).

\footnotetext{
* Agradeço a Sílvia Portugal pela leitura atenta de várias versões deste artigo e pelas suas sugestões. Todos os problemas que permaneçam são, porém, da minha inteira responsabilidade.
}

DADOS - Revista de Ciências Sociais, Rio de Janeiro, vol. 57, no1, 2014, pp. 167 a 197. 
O paradigma do dom é relevante para o estudo do fenômeno dos sem-abrigo por motivos epistemológicos, políticos e ontológicos. Uma vez que este artigo olha para um contexto de vida na rua numa sociedade capitalista liberal ocidental, as negações da realidade habituais nas reflexões dominantes sobre este modelo sociopolítico são facilmente identificáveis também nos discursos sobre tal fenômeno. Um dos pontos fortes da teoria do dom é a reflexão sobre o que ocorre para além do Estado e do mercado, nas relações não oficiais entre os sujeitos. No caso do objeto deste estudo, encontra-se uma tendência para encará-lo como algo que é motivado por falhas nestas duas esferas de regulação social, pressupondo-se que quaisquer soluções deverão também daí provir. Sem dúvida que o papel do Estado e do mercado é fulcral no tocante às causas do fenômeno e que qualquer solução para ele terá de comportar uma reorganização profunda destas esferas. Chegar à rua é indicador de que os mercados laboral e habitacional estão estruturalmente organizados de um modo que impossibilita uma parte dos indivíduos de acedê-los com segurança e estabilidade. É também uma expressão bem visível de que as políticas públicas implementadas pelo Estado são incapazes de chegar aos cidadãos mais desprotegidos - e que mais precisam delas -, pelo menos de um modo significativo para garantir o bem-estar mínimo a que estes não conseguem ter acesso pelo mercado. Contudo, há fatores que contribuem para causar o fenômeno dos sem-abrigo que se encontram fora do Estado e do mercado, sendo ele explicável pela conjugação de falhas de proteção dos sujeitos nas três esferas de regulação social - Estado, mercado e dádiva.

Assim, para que o problema seja compreensível e solucionável, temos de olhar também as relações interpessoais informais. Estas podem ou não fornecer apoio aos envolvidos, substituindo ou complementando o Estado e o mercado como meios de obtenção de recursos, e, desta forma, facilitar ou dificultar que os indivíduos cheguem à rua. Chegar e continuar a viver na rua é, assim, também motivado por uma incapacidade de obtenção de bens, dinheiro e habitação através das redes de sociabilidade primária. As relações de dádiva em que os atores sem-abrigo são donatários não são suficientes para assegurar-lhes, por si sós, o que o Estado e o mercado não garantem. O dom pode substituir as outras duas esferas em situações pontuais, mas, em um nível longitudinal, no caso de quem se torna sem-abrigo, não é qualitativa nem quantitativamente suficiente para proteger os indivíduos. Também a solução dos problemas associados ao fenômeno dos sem-abrigo pode provir de fora do Estado e do mercado, sendo que ele não é solucionável 
como um todo sem alterações nas relações interpessoais não oficiais. Isto vale quer falemos da desqualificação social e da estigmatização que só são minimizáveis por interações no registro da sociabilidade primária, quer falemos da obtenção cotidiana de dinheiro, comida, roupa, trabalho temporário ou outros recursos, que, muitas vezes, ocorrem por via não oficial neste objeto de estudo. Mas vale também para a solução do problema - a falta de casa -, também ela podendo provir desta esfera extraestatal e extramercantil. Não defendo que o sistema da dádiva seja suficiente per se para eliminar o fenômeno; ele não tem esse potencial, tal como as outras duas esferas não o têm. Uma solução tem de vir da complementaridade dos três sistemas de regulação e cada um deles precisa ser reorganizado para que a solução se torne possível, mas tal só poderá se tornar numa realidade se rejeitarmos a negação do que está fora do Estado e do mercado.

Se os motivos epistemológicos e políticos que tornam importante estudar as relações de dádiva caracterizadoras do fenômeno dos sem-abrigo são os expostos, há ainda uma questão ontológica que força a reflexão sobre o fenômeno a contemplar o dom. As negações referidas devem-se, em grande medida, à hegemonia do utilitarismo. Esta corrente tem um modo particular de observar o mundo e as interações humanas que parte de uma concepção específica (e naturalizada) do ser humano como homo economicus. Com base nesta visão, o mundo torna-se um conjunto atomizado de seres humanos dotados de racionalidade instrumental em busca permanente da maximização do seu bem-estar individual e dos seus interesses próprios. Tudo o que não é caracterizável através desta construção é invisibilizado ou pervertido de modo a tornar-se legível através das lentes enviesadas que o utilitarismo fornece. Entenda-se: o interesse por si existe, tal como existe a racionalidade instrumental, mas, ao seu lado e de modo concomitante, há outras realidades, tão fundamentais para entender as sociedades contemporâneas - e logo, o fenômeno dos sem-abrigo - quanto as anteriores. A revisão ontológica do mundo é um dos passos para mudá-lo e um dos passos para que o possamos compreender - se o homo economicus é tudo o que aceitamos que exista, então, resta-nos continuar a reproduzir as mesmas ausências que o utilitarismo produz e continuar a não entender o papel da dádiva nos diversos espaços da sociedade. Os indivíduos são atores racionais e estratégicos, mas isto não é tudo o que eles são. Ao lado do homo economicus, encontramos também o que Godbout (2000) caracteriza como homo donator, o ator envolvido numa relação de dom que rejeita o cálculo ubíquo. Isto vale para a rua do mesmo 
modo que vale para outras figurações. A racionalidade estratégica é fundamental para que os atores sem-abrigo consigam sobreviver (Snow e Anderson, 1993; Zeneidi-Henry, 2002; Rullac, 2005; Damon, 2008; Aldeia, 2011) e cria um homo economicus dirigido para fins de sobrevivência cotidiana e que mobiliza meios bem mais escassos do que os disponíveis aos sujeitos domiciliados. Mas a rua não é ontologicamente idiossincrática: também nela os seres humanos são mais complexos do que o utilitarismo admite. O paradigma do dom é especialmente adequado para desfazer esta construção ontológica que também encontramos nas reflexões sobre o fenômeno dos sem-abrigo.

O texto divide-se em duas seções. Na primeira, esboço as principais características do paradigma da dádiva. Na segunda abordo o lugar da dádiva no fenômeno dos sem-abrigo recorrendo ao material empírico produzido em um trabalho anterior (Aldeia, 2011), na qual analisei o papel dos laços sociais neste campo de investigação. Com base neste material, olho para as relações de dom que um indivíduo sem-abrigo desenvolve com a sua família, para o acesso ao espaço de pernoite na rua, entendido como manifestação de uma forma de dádiva atípica, e para os sentimentos de dominação criados por relações de dádiva indesejadas.

\section{A CENTRALIDADE DA DÁDIVA}

Independentemente da intenção de desvendar as dimensões não declaradas das interações humanas que os estudos sociais tantas vezes afirmam, estes têm uma tendência para olhar, sobretudo, para a vida social oficial e pública. Daqui derivam as duas principais negações referidas: a exclusividade analítica do Estado e do mercado enquanto loci da regulação social e a negação do "homo extra-economicus". Considerando estas invisibilizações insustentáveis, torna-se necessário que os estudos sociais deem conta das dimensões não oficiais da vida social que estão para além do Estado e do mercado e reconheçam as características dos seres humanos modernos ocidentais não abarcáveis pelo homo economicus (Godbout e Caillé, 1997; Caillé, 2000; Godbout, 2000; Portugal, 2006, 2011).

Poucas correntes teóricas têm desenvolvido esforços mais consistentes de alargamento da nossa compreensão do mundo do que a perspectiva do paradigma da dádiva, encabeçada pelo M.A.U.S.S ${ }^{1}$. Para esta corrente, a dádiva permanece fundamental para a circulação de bens e ser- 
viços nas sociedades modernas ocidentais. As interações sociais não são somente reguladas ora pelo Estado, ora pelo mercado (ou pela complementaridade dos dois princípios). Ao lado delas, o dom forma "um sistema, não sendo esse sistema outra coisa do que o próprio sistema social enquanto tal. $\mathrm{O}$ dom constitui o sistema das relações propriamente sociais enquanto estas são irredutíveis às relações de interesse económico ou de poder" (Godbout e Caillé, 1997:22). A dádiva não só é, por vezes, uma alternativa ao Estado e ao mercado, como, muitas vezes, surge a par destes princípios, complementando-os e suportando-os. Tanto a nível qualitativo como quantitativo, o dom é essencial nas sociedades contemporâneas (Godbout, 1996; Godbout e Caillé, 1997; Caillé, 2000; Godbout, 2000; Portugal, 2006, 2011).

Adotemos a definição de dádiva avançada por Godbout e Caillé:

qualifiquemos de dom toda a prestação de bens ou de serviços efetuada sem garantia de retribuição, tendo em vista criar, alimentar ou restabelecer os laços entre as pessoas. Propomo-nos ver como o dom, assim caracterizad o como modo de circulação de bens ao serviço dos laços sociais, constitui um elemento essencial a toda a sociedade (Godbout e Caillé, 1997:30).

Na dádiva, então, o fundamental não é tanto o que circula quanto o laço pelo qual o bem ou o serviço circula. Circular ao serviço do laço significa que o laço é mais importante do que a coisa que circula, que apenas ganha sentido quando é inserida numa relação (Godbout e Caillé, 1997; Caillé, 2000; Godbout, 2000; Portugal, 2006, 2011).

Desde Mauss (2008) e em alguns de seus principais comentadores ${ }^{2}$ a dádiva é inserida no ciclo tripartido de "dar, receber e retribuir", três momentos frequentemente sobrepostos na circulação de bens e serviços através dos laços. A importância dos três momentos é consensual entre os autores do paradigma, ainda que o peso atribuído a cada um seja variável. Desde o Ensaio sobre a Dádiva (Mauss, 2008), a retribuição surge como o momento privilegiado pela análise (Godbout, 1996). Contudo, apesar desta ser importante, secundarizar os atos de dar e de receber ao de retribuir é um modo de perverter o sistema do dom, negando a sua existência, submetendo-o ao modelo mercantil. Se a retribuição é mais relevante do que o ato de dar, então, dou para receber, buscando uma equivalência relacional entre bens e serviços que circulam. Para mais, se a retribuição é o momento privilegiado, então, o dom é pura obrigação, não havendo nele espaço para a liberdade. A re- 
tribuição, do ponto de vista utilitarista, é o momento de restabelecimento do equilíbrio perdido aquando da dádiva inicial, é a eliminação da dívida (Godbout e Caillé, 1997; Caillé, 2000; Godbout, 2000).

Olhando a circulação das coisas a partir do dom, a realidade dessa circulação complexifica-se. O ciclo "dar, receber, retribuir" tem uma dimensão de constrangimento, de obrigação, mas comporta também liberdade, espontaneidade, incerteza. A busca de equivalência pode ser relevante para os envolvidos, mas esta não pode ser entendida de modo mercantil: a equivalência mercantil é o fim da dádiva, o fim da relação, o momento de reposição de equilíbrios em que a relação volta ao estado inicial, prévio ao dom. Ora, ao contrário do mercado, que se caracteriza pela equivalência, e do Estado, caracterizado pela igualdade legalmente assegurada, o dom afasta-se do cálculo (instrumental) e funda-se na dívida entre os envolvidos (Godbout e Caillé, 1997; Caillé, 2000; Godbout, 2000; Portugal, 2006, 2011). Uma relação de dom "saudável" é aquela em que cada um dos envolvidos sente que recebe mais do que dá; é uma relação marcada pelo estado de dívida mútua positiva inconcebível pelo mercado (Godbout e Charbonneau, 1993; Godbout, 2000). Seguindo Portugal (2006), a equivalência não está ausente no dom, mas este tem propriedades "alquímicas", tornando "equivalente" o que não o é, dado que o que circula se subordina ao laço por onde circula ${ }^{3}$. Como defendem Godbout e Caillé,

a equivalência não está ausente [da] relação de dom. Mas é apenas um elemento dela, que não poderá ser central. A equivalência está simultaneamente presente e ausente, no sentido em que:

- não é possível fugir-lhe demasiado, sem se considerar que, em lugar de dar, se "está a perder";

- mas também não é possível aproximarmo-nos demasiado dela, liquidar a dívida sem pôr fim à relação.

Quando a aproximação é excessiva, um dos parceiros realiza um gesto que rompe a equivalência, uma loucura, um excesso que afasta de novo os parceiros do equilíbrio. O campo da dívida situa-se entre estes dois pólos, e o estado de dívida recíproca, voluntariamente mantido, será o seu estado normal. Por outro lado, a própria equivalência é de um tipo diferente da equivalência mercantil, porque ela tem em conta as características pessoais dos agentes, os seus níveis de rendimento, as suas necessidades, etc. (1997:48). 
Então, a dívida é o estado normal da relação de dádiva: a equivalência pode ser buscada mas não é atingida (sendo "encontrada" de modo "alquímico"). Quando a relação se torna equivalente, reduz-se à troca mercantil, o que acaba a relação de dádiva, sendo possível que se extingua o laço.

O dom é também caracterizado pela dicotomia liberdade/constrangimento. A dívida funda-o, mas, sendo não mercantil, é não contratual, e logo, pode não ser paga. Do mesmo modo, não há coercividade estatal a exigir que se cumpra uma obrigação. "Coercividade" existe, é certo, mas sempre de modo incerto, inseguro. O dom é, talvez acima de tudo, paradoxo. Ele tem uma normatividade própria e há consequências, por vezes dramáticas, para o envolvido numa relação de dom que quebre as suas obrigações. Mas, acima de todas as outras obrigações, até mesmo as de "dar, receber e retribuir", está a "obrigação de não explicitar a obrigação". A normatividade da dádiva é conhecida por todos os envolvidos, mas parte intrínseca dela é o fato de dever permanecer não mencionada (Godbout, 1996; Godbout e Caillé, 1997; Caillé, 2000; Godbout, 2000; Portugal, 2006, 2011). Assim, é obrigação do doador procurar libertar o donatário das suas obrigações, realçando o caráter livre de ambos na dádiva ("sou livre de dar, tu és livre para receber, e, sobretudo, livre para retribuir"), sabendo à partida os envolvidos que nenhum deles fica inteiramente livre na relação. Ultrapassando a estéril discussão acerca da honestidade ou da hipocrisia dos envolvidos, o fato de existirem obrigações de parte a parte só é sentido pelos envolvidos como negativo se a dívida for indesejada. Se esta for querida, não é em si mesmo problemático que se criem obrigações na relação. O dom, deste modo, é livre $e$ obrigatório; é constrangimento $e$ espontaneidade; tentativa de reciprocar $e$ gratuidade de gestos sequenciais.

A negação da normatividade só é compreensível como uma "negação hipócrita das reais intenções dos sujeitos" caso o que circula seja entendido como mais relevante do que o laço por onde circula; caso os bens e serviços sejam percebidos pelo modelo mercantil, que apenas percebe as coisas como tendo valor de uso e de troca. Mas a dádiva tem também o valor simbólico de incorporar uma parte da essência do sujeito que dá - o hau maori de que falava Mauss (2008) -, um valor simbólico que está para além do que (também) existe no mercado ${ }^{4}$ : o dom tem, sobretudo, valor de elo (Godbout, 1996; Godbout e Caillé, 1997: 244-247; Caillé, 2000; Godbout, 2000; Portugal, 2006, 2011). Como defendem Godbout e Caillé, 
ao circular, o dom enriquece o laço e transforma os protagonistas. $\mathrm{O}$ dom contém sempre um além, um suplemento, qualquer coisa mais, que a gratuidade tenta nomear. É o valor de laço. (...) na oferta de um presente, o objectivo não é dispor de um mecanismo que permita uma perfeita correspondência com as preferências do donatário. A aposta do presente é que o doador demonstre que sabe de que é que o donatário gosta [ou precisa; o essencial é que o doador mostre conhecer o donatário e atender aos seus gostos e necessidades]. Isso é mais importante do que a satisfação "mercantil" do donatário, pois é o laço que conta, e o dom é uma operação ao serviço do laço. (...) não há escala econômico, pois o valor de laço depende das características das pessoas, da natureza do laço, de um conjunto de variáveis que o valor económico, para se formar e se tornar puramente quantitativo, teve de expurgar inicialmente (1997:245-246).

É pelo valor de laço que o dom se reveste da característica paradoxal (do ponto de vista mercantil ou estatal) de "obrigação livre". Não só obrigação $e$ liberdade, mas obrigação com liberdade (ou liberdade com obrigação). O dom não é gratuito mas tem um componente de gratuidade. Só por ele é possível que as coisas circulem ao serviço do laço. $\mathrm{O}$ dom é "gratuito" na medida exata em que tem uma carga de espontaneidade e em que cria incerteza nos envolvidos na relação ("dou, mas posso não receber"; ; dou, mas podem não aceitar"; "recebo, mas posso não retribuir"). $\mathrm{O}$ incumprimento das obrigações tem consequências, mas é pela liberdade do dom que é demonstrada a confiança no outro, essencial à relação. É certo que a confiança não está ausente do mercado ou do Estado, mas o contrato, o imposto, e o monopólio da violência "legítima" são mecanismos de redução da incerteza presente na troca, na circulação de bens e serviços. Na dádiva, tais mecanismos oficiais estão ausentes. Dou e o outro recebe (ou não recebe). Ao receber, o donatário agradece, realça a obrigação ("obrigado"), mas o doador procura libertá-lo da sua obrigação ("não é nada"). Só veiculando uma imagem de liberdade a retribuição se torna insegura. Só sendo insegura, incerta, é possível que, no gesto de dar, esteja implícita a confiança no outro, confiança de que o outro cumpra as suas obrigações e que não o faça por se sentir obrigado mas precisamente por se sentir livre para fazê-lo (Godbout, 1996; Godbout e Caillé, 1997; Caillé, 2000; Godbout, 2000).

Mas o dom tem gratuidade e liberdade (não sendo nem gratuito nem livre) também pelos seus diferentes momentos (dar, receber, retribuir) 
se sobreporem. O corte entre eles é analítico e não empírico. Na praxis, os momentos do dom mesclam-se totalmente. Ao dar, recebo. Ao receber, retribuo. Ao retribuir, dou. Tal não significa que o interesse por $\mathrm{si}^{5}$ seja o fator preponderante no dom ("dou porque gosto de dar, o que éo mesmo que dizer que satisfaço o meu egoísmo"). O interesse por si não está ausente, mas reduzir a ele todo o dom é simplificar a questão; é retirá-la da dádiva para colocá-la no mercado. Dar e receber não é o mesmo que dar para receber, tal como não é igual dar para receber a satisfação de dar e dar para que me retribuam sob a forma de bem ou serviçomesmo que tal retribuição se verifique (Mermet, 1991; Godbout, 1996; Godbout e Caillé, 1997; Caillé, 2000; Godbout, 2000; Caillé, 2006; Portugal, 2006, 2011).

\section{DAR, RECEBER E RETRIBUIR NO FENÔMENO DOS SEM-ABRIGO}

Presenciei recentemente uma discussão entre dois indivíduos semabrigo em que estes aparentavam discordar fundamentalmente sobre o que a rua significa. Para um deles, "a rua nada tem de bom"; para o outro, "tem tudo de bom". Aos meus olhos, a discordância aparente não era tão grande quanto poderia parecer, no momento da discussão, para os intervenientes. O que estava em causa era, sobretudo, a complexidade e o caráter paradoxal da vida na rua. A violência, os roubos, as carências, o estigma, o desrespeito e o cálculo individual coexistem, na rua, com o apoio, a camaradagem e a partilha de bens escassos. Olhar só para um dos lados é ter uma leitura parcial do fenômeno dos sem-abrigo. Viver na rua é uma injustiça social tremenda, isso é ponto assente, tanto para mim quanto para os dois sujeitos que discutiam e que experienciam na pele essa injustiça. Mas, no meio de tudo o que falta a quem vive na rua, há laços que se desenvolvem, há apoio, há reciprocidade sem cálculo instrumental (Snow e Anderson, 1993; Gowan, 2010; Aldeia, 2011). Pelos laços, circulam coisas; aliás, os laços existem pois por eles algo circula.

Se a rua tem dimensões não negativas, estas não derivam do Estado ou do mercado. Tais esferas estão presentes, mas de um modo que reafirma a injustiça de viver na rua. O mercado é a esfera a qual só se pode aceder em posição desfavorável, onde só bens baratos se podem comprar, muitas vezes de má qualidade. O Estado está presente pelas transferências mínimas (em particular, o Rendimento Social de Inserção ${ }^{6}$ - RSI) e pelas diversas instituições com que os sujeitos sem-abrigo contatam (a polícia, a Segurança Social, as instituições do Terceiro Se- 
tor parceiras do Estado), mas estas relações realçam uma posição oficial de inferioridade face à cidadania, consubstanciada na negação do "direito a ter direitos" (Feldman, 2006; Lyon-Callo, 2008; Gowan, 2010; Aldeia, 2011). Ser "sem-abrigo" é uma posição permanentemente desqualificada e não é sob essa condição que quem vive na rua pode minimizar a negatividade da sua situação. Só enquanto pessoa é possível minimizar a violência simbólica e material da vida na rua. É por isso que tal não é alcançável através das duas esferas referidas. A minimização do mal-estar de ser "sem-abrigo" só é realizável pela interação na sociabilidade primária; não pela que ocorre nas esferas da sociabilidade secundária. Para Caillé,

designemos por sociabilidade primária o tipo de ligação social onde a personalidade das pessoas importa mais do que as funções que elas desempenham (o que não impede essas funções de existir e de importar). E sociabilidade secundária, o tipo de ligação submetido à lei da impessoalidade (como no mercado, no direito ou na ciência), onde as funções desempenhadas pelas pessoas importam mais do que a sua personalidade (2000:128, ênfases no original $)^{7}$.

Um dos principais problemas da vida na rua é o fato dos sujeitos sem-abrigo, ao nível da sociabilidade secundária, não cumprirem qualquer função percebida como positiva pela sociedade em que vivem. À desqualificação enquanto "sem-abrigo", perante as enormes dificuldades de sair da rua para uma posição estruturalmente menos desqualificada, só se pode contrapor de um modo positivo a qualificação como pessoa, como ser humano inserido em redes interacionais. Como Godbout e Caillé defendem: "o dom constitui o modo de relação por excelência entre as pessoas enquanto elas se constituem e instituem como pessoas. Ele é aquilo que transforma os seres e os indivíduos em pessoas. Corolário: o dom institui o registro da 'sociabilidade primária', de que forma a própria trama" (1997:197). É no espaço da dádiva que a desvalorização estatutária de ser "sem-abrigo" pode ser combatida, ainda que, como veremos, tal não signifique que todas as relações de dom permitam combater esta desqualificação.

\section{Metodologia}

Os dados empíricos discutidos neste texto dizem respeito à história de vida de Rui Botelho, um indivíduo sem-abrigo, produzida no âmbito de uma observação direta mais ampla, levada a cabo entre dezembro de 2010 e junho de 2011. Duas questões metodológicas relevantes para 
a análise da dádiva no fenômeno dos sem-abrigo derivam deste procedimento. Em primeiro lugar, defendo a perspectiva segundo a qual, para entendermos a realidade da vida na rua, é fundamental analisarmos intensivamente as biografias dos atores sem-abrigo (Aldeia, 2011). Como Rui Botelho me disse uma vez, "cada pessoa tem uma história", e essa(s) história(s) deve(m) ser conhecida(s) e analisada(s) para compreendermos o fenômeno de um modo intensivo e longitudinal. Tal procedimento metodológico não nos permite induzir dados do caso de nível micro estudado para a macrorrealidade em que a questão existe. Mas tal só é um problema se o propósito do conhecimento que produzimos for a generalização, e esta está fora do âmbito deste texto. O caso estudado é tido como exemplar do fenômeno dos sem-abrigo, seguindo a perspectiva defendida por Pais: "ao estudar-se um caso, o objetivo não é o de representar o mundo; basta a representação do caso. Aliás, um caso não pode nunca representar o mundo, embora possa representar um mundo no qual muitos casos semelhantes acabam por se refletir" (2003:109). Assim sendo, epistemológica e metodologicamente, uma única biografia é suficiente na medida exata em que o caso não se afirma como representativo do fenômeno em que se insere, mas sim como exemplar. Sendo exemplar, ele não é idiossincrático: a vida de Rui Botelho apresenta semelhanças com outras vidas, e estas parecenças não devem ser subvalorizadas.

A segunda questão metodológica prende-se com o estudo do dom. O dom é relacional, pelo que Godbout (2000:15) defende a sua análise através do que designa como "método dos olhares cruzados". Em linhas gerais, esta proposta implica que o pesquisador fale com os diferentes atores na circulação de um dom, com os diversos participantes numa relação de dádiva, para apreender o sentido que cada um deles confere ao que circula ao serviço do laço. O dom é, afinal, uma relação, não um ato isolado, pelo que é ao abordar um mesmo fenômeno sociológico - uma relação de dom - a partir dos diferentes pontos de vista nele envolvidos que é possível obter uma compreensão completa da relação. Ao olhar para a dádiva no fenômeno dos sem-abrigo a partir de uma história de vida, o método dos olhares cruzados não é uma possibilidade ao dispor do investigador. Seria, sem dúvida, melhor ter tido acesso às perspectivas dos outros envolvidos nas relações de dom em que Rui se insere, mas não foi com o propósito de estudar a dádiva que o meu trabalho de campo foi desenvolvido. O que queria era entender a importância de laços sociais de diferentes tipos de vida na rua (Aldeia, 2011), e, para este propósito, a perspectiva de quem vive na 
rua era suficiente. Mas, se era suficiente para entender o papel dos laços, não é também suficiente para entender o que por eles circula? Se o dom é, acima de tudo, relação, então, ele ganha significado para os envolvidos, e os significados que cada um deles lhe atribui serão diferentes, ainda que possam partilhar certas características. Assim sendo, abordo o dom como abordei os laços: a partir do que este significa para um dos envolvidos, considerando que ele não é nem mais nem menos relevante para a relação de dádiva do que os outros envolvidos, mas que o modo como ele - sem-abrigo - experiencia esta relação é mais importante para compreender o papel da dádiva na vida na rua do que as perspectivas dos indivíduos domiciliados nela envolvidos. É certo que há dom na rua entre atores sem-abrigo, mas, dado que a vida de Rui é tida como exemplar, então, ela constitui um ponto de entrada no estudo do fenômeno tão legítimo quanto qualquer outro.

\section{A VIDA DE RUI BOTELHO}

Rui Botelho tem 53 anos. Filho de uma família pobre das classes populares, foi entregue pelos pais a uma instituição logo após o seu nascimento. Aí permaneceu até os 12 anos, quando os pais o foram buscar com o objetivo de ir trabalhar e ganhar dinheiro para a família, passando a viver com os pais e os nove irmãos e irmãs desde então. Com um percurso profissional irregular, majoritariamente no setor da construção civil, apenas deixou de trabalhar durante os períodos em que esteve preso, num total de 11 anos entre dois encarceramentos. Com 17 anos, conheceu a companheira com a qual teve dois filhos. A relação foi mal recebida pela família de Rui, motivando uma série de conflitos e mais de uma expulsão da casa familiar onde viviam. Após alguns dos episódios em que o casal e os filhos foram forçados a deixar a casa dos pais de Rui, foram acolhidos por outros familiares - uma tia noutra cidade, por algumas semanas; uma irmã de Rui, durante alguns meses. Contudo, a passagem pela prisão enfraquece os laços com a família, terminando a relação com a companheira, deixando de falar com os filhos e de poder contar com os irmãos após a saída da cadeia, pelo menos, tanto quanto contava anteriormente. Na viragem do século $\mathrm{XX}$ para o XXI, saído da prisão e novamente a trabalhar na construção civil, um problema de saúde adiciona-se a uma crescente dificuldade em encontrar emprego no setor e ao sentimento de que não podia contar com o apoio familiar, motivando uma emigração, primeiro para a Espanha, depois para a França. Aí, torna-se sem-abrigo pela primeira vez, ainda que apenas durante alguns dias. Após esse período, passa a 
viver com uma família portuguesa emigrada na França, obtendo emprego na empresa de construção civil para a qual trabalhava também o marido do casal emigrante. Vive cerca de 6 meses com esta família, desenvolvendo o que considera terem sido os laços mais fortes que conheceu desde a separação da companheira. Porém, passado esse período, uma situação de conflito crescente com a família emigrante leva a que Rui regresse a Portugal. Só, sem dinheiro nem apoio familiar, permanece por alguns meses na casa de um amigo próximo. Sentindo-se um "fardo" - devido a problemas que sentia que a sua presença criava junto da família do amigo - decide sair da casa dele. Sem lugar para onde ir, torna-se sem-abrigo, situação em que se encontra há 4 anos. Aí, o apoio, quer familiar, quer estatal, é reduzido e não lhe permite sair da rua. Apesar da violência, ansiedade e receios que marcam a vida na rua, é também nesse espaço que Rui vai desenvolver uma série de laços com outros indivíduos sem-abrigo e sujeitos que, ainda que domiciliados, têm posições estruturalmente pobres e dominadas semelhantes à sua. O único familiar com o qual mantém uma relação próxima, mesmo que conflituosa, é Nuno, um irmão mais novo com o qual interage frequentemente.

\section{A Hospitalidade}

Godbout (2000: 20 et passim) distingue três tipos de dons familiares: os bens, os serviços e a hospitalidade. Qualquer destes tipos pode circular segundo dois registros: o da ajuda e o da prenda - "a hospitalidade pode ser de tipo 'ajuda' (abrigamos alguém que se separou ou que está a mudar de casa) ou de tipo 'prenda' (recepções, festas)" (Godbout, 2000:31). Ao longo da vida, Rui foi temporariamente apoiado por familiares através de dádivas de hospitalidade, por mais de uma vez. Porém, atualmente, nenhum familiar se disponibiliza para acolhê-lo, embora todos eles saibam que vive na rua. Vários conflitos familiares, agravados pela passagem pela prisão, reduziram os fluxos de apoio que os familiares lhe dirigiam. Mas nem sempre assim foi. A família é fundamental para os indivíduos garantirem o acesso à habitação (Portugal, 2006) e o foi no caso de Rui por algumas vezes, ainda que sempre de um modo marcado pelo conflito. Recorrentemente, foi recebido em casa de familiares durante o início da idade adulta, com a companheira e os filhos. Mas sempre sentiu que a sua presença era causadora de mal-estar junto aos demais habitantes da(s) casa(s). Poucos dias após nascer o filho mais velho, Rui e a companheira foram expulsos da casa dos pais de Rui onde viviam juntamente com vários dos 
seus irmãos e irmãs. A razão apresentada foi o fato de a criança recém-nascida fazer demasiado barulho, o que incomodava o restante dos habitantes da casa. Rui, contudo, sempre considerou que esse motivo escondia o fato real pelo qual foram expulsos: a sua relação com a companheira, ainda oficialmente casada com outro homem, fora sempre mal vista pela sua família. Saídos da casa dos pais de Rui, foram acolhidos por uma tia dele, que residia noutra cidade. Nessa casa ficaram apenas cerca de duas semanas, sendo novamente expulsos por a tia considerar que a presença de outras pessoas em casa a perturbava. Alguns anos depois, após o nascimento do segundo filho, de novo sem casa, foram acolhidos por uma das suas irmãs. Dessa vez, permaneceram por vários meses hospedados. Mas, novamente, acabaram por ter de sair, devido a conflitos criados entre os habitantes da casa. Segundo Rui, a irmã nunca havia gostado da sua companheira e incentivara-o a desenvolver uma outra relação amorosa com uma mulher a quem o tinha apresentado. Os problemas decorrentes do fato da companheira de Rui ter tomado conhecimento da situação levaram a que o casal tivesse de mudar de habitação.

Assim, encontramos uma regularidade nesta forma particular de apoio familiar. A dádiva existe e é significativa: quando precisava, algum familiar lhe disponibilizava habitação. Mas tão rapidamente quanto a dádiva era feita, era também retirada. A indeterminação característica do sistema de dom atinge, na vida familiar de Rui, proporções consideráveis. O dom é em si mesmo inseguro, não contratual ou legalmente assegurado. Porém, em vários casos em que Rui foi donatário de familiares, esta insegurança prende-se não com a possibilidade da dádiva não ser retribuída (direta ou indiretamente) mas, antes, com a possibilidade dela ser retirada depois de dada. Recorrentemente, "a mão é estendida" apenas para ser depois recolhida, o que não garante estabilidade através dos laços familiares.

Apesar de Caillé (2000) afirmar que a dádiva é agonística, é uma forma de guerra, as reflexões habituais sobre ela tendem a subvalorizar o conflito e a insegurança que caracterizam as relações de dom. O princípio de que "uma mão dá e a outra retira" diz-nos várias coisas. Desde logo, é significativo que a dádiva seja realizada. Os sentimentos de obrigação familiar e o desejo de dar explicam isto, em particular, dado que estes sentimentos são especialmente fortes nas relações familiares (Portugal, 2006). Porém, a obrigação e o prazer de dar não têm força suficiente para, em todos os casos, se sobreporem, ao longo do tempo, ao 
mal-estar e aos inconvenientes sentidos pelos envolvidos na relação de dom. Com o passar do tempo, os sentimentos de obrigação e/ou de prazer que levaram ao dom vão perdendo força perante os fatores causadores de mal-estar. O conflito torna-se mais relevante na relação, le-

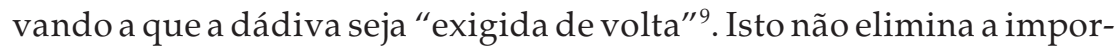
tância interacional ou sociológica do gesto de dar, mas complexifica a relação de dom. Deste modo, torna-se fundamental contextualizarmos a relação de "dádiva-feita-dádiva-desfeita" de modo estrutural e circunstancial. Sendo a hospitalidade um dom atuante ao longo de um período de tempo mais ou menos longo, o contexto em que o dom é feito vai sendo alterado pela interação continuada dos envolvidos, criando um contexto final diferente do inicial, já não propenso à dádiva. $\mathrm{O}$ que gera conflito é a partilha de recursos (as contas no final do mês atingem montantes superiores, o espaço da casa disponível a cada habitante reduz-se, a privacidade é diminuída, dificultando a recomposição do self no final de um dia de trabalho, dado que mais habitantes equivalem a mais barulho, a mais atividades no mesmo espaço).

Mas esta partilha é particularmente geradora de conflito quando o contexto em que ocorre é um de escassez. A família de Rui é pobre, ainda que diferentes elementos conheçam situações de pobreza diferenciada. Quando os recursos são já escassos para um agregado familiar, partilhá-los entre mais elementos torna-se difícil. Mesmo que as pessoas queiram ajudar os familiares, não sentem ter condições socioeconômicas para o fazerem. A pobreza explica, em grande medida, o fato de o dom ser retirado depois de dado. Os sentimentos de obrigação e/ ou de prazer que levam ao ato de apoiar um familiar são sentidos ao longo da estrutura socioeconômica, mas quando há mais recursos para partilhar, o conflito demora mais tempo a desenvolver-se. Em estratos sociais estruturalmente mais elevados, os donatários precisam de menos ajuda e precisam dela durante menos tempo, e os doadores têm maiores possibilidades de apoiá-los. A relação torna-se mais complicada quanto mais descemos ao longo da estrutura socioeconômica, alterando-se os equilíbrios entre a ajuda necessária e a ajuda passível de ser dada.

\section{O Irmão Nuno}

Como é visível pelo dom de hospitalidade, as relações que Rui mantém com os familiares são, sobretudo, tensas e conflituosas. Isto é válido para todas as relações familiares, ainda que não diminua a sua impor- 
tância, que "é significativa mesmo quando os laços não são positivos (...). As relações de conflito e de ruptura das relações familiares são sentidas com dor pelas pessoas que as revelam" (Portugal, 2006:493).É neste contexto que mescla conflito e apoio que se torna relevante olhar para a relação que Rui mantém com o irmão mais novo.

Atualmente, apesar de não ser sem-abrigo, Nuno é o familiar que tem uma posição estrutural mais semelhante à de Rui: ambos estão desempregados, ambos têm no RSI a única fonte regular de rendimento, ambos mantêm uma relação tensa com o resto da família. A relação entre os irmãos foi sempre conflituosa, marcada por rupturas e reaproximações frequentes, mas é, apesar disso, fundamental para a vida de Rui e claramente caracterizada pelo apoio recíproco. Por várias vezes, os irmãos trabalharam e/ou viveram juntos, apesar de Rui afirmar que essa interação cotidiana foi sempre conflituosa. A relação é particularmente significativa pela empatia entre ambos, construída com base na rememoração do passado familiar e na indignação e na injustiça sentidas face ao Estado, face à incapacidade de acederem o mercado de trabalho regular e ao que percebem como uma falta de apoio do resto da família. Entre os irmãos, o dom é frequente, sob a forma de dinheiro, de bens, de camaradagem, de apoio emocional. $\mathrm{O}$ fato de se privilegiar a perspectiva de Rui, como foi referido, impede o "cruzamento metodológico dos olhares" defendido por Godbout (2000:15) para a análise da relação de dom. Contudo, não estamos no registro da dívida mútua positiva. Na ausência da perspectiva de Nuno, estamos perante uma dívida sentida como unilateral ou como negativa (Godbout e Charbonneau, 1993:238).

O essencial, dada a entrada metodológica pelo olhar de Rui, é o fato de este sentir que dá - que sempre deu - mais do que recebe na relação. Tal não invalida que considere ser também donatário: pelo menos por uma vez desde que está na rua, acedeu um trabalho precário e temporário através do irmão. Do ponto de vista da narrativa veiculada por Rui, tal representação de si mesmo como o principal doador da relação permite autoapresentar-se de modo positivo. Como veremos mais adiante ao abordar a relação com as instituições "assistencialistas", esta posição positiva enquanto doador apenas é possível para Rui nas suas interações com sujeitos igualmente dominados e pobres, neste caso, com o irmão. Dado que uma relação (como a "assistencialista") em que o sujeito é permanentemente relegado para uma posição negativa de donatário sem capacidade para se tornar doador é injuriosa, desqualificado- 
ra, colocar-se primordialmente do lado da doação (e não da recepção) na relação com Nuno é um modo de Rui combater de modo tênue e parcial a desqualificação e a estigmatização que o fato de ser "sem-abrigo", "pobre" e "assistido" acarreta na maioria das suas interações com indivíduos domiciliados. Mas as situações em que Rui é donatário nesta relação são também significativas, reforçando a ideia já constatada sobre o dom de hospitalidade, de que as relações de dádiva que Rui estabelece com familiares são caracterizadas, sobretudo, pelo conflito, pela insegurança e pela instabilidade. Também no caso em que Nuno arranjou trabalho a Rui, "uma mão dá e a outra retira". A pós conseguir trabalho para o irmão, conta ao empregador de ambos que Rui vive na rua. Na posse desta informação, o empregador decide pagar a Rui um salário inferior ao acordado informalmente, por considerar que, vivendo na rua, Rui aceitaria vender o seu trabalho em troca de menos dinheiro. A situação degenera em conflito, chegando à violência física de modo a obrigar o pagador em falta a cumprir com o que fora inicialmente acordado.

O laço entre os irmãos, neste caso como em outros, está permanentemente envolvido em conflito e em tensão, apesar disso não o eliminar, nem invalidar futuras trocas de dons através dele. O laço é desejado, fornece um apoio fundamental a ambos os envolvidos, pelo que os problemas associados às dádivas que por ele circulam são suportados. Isto demonstra o caráter secundário daquilo que se desenvolve diante da relação onde circula: nesta relação, o valor de elo sobrepõe-se às negatividades das dádivas específicas dado que o laço é desejado pelos envolvidos.

\section{O Espaço de Pernoite na Rua}

Quando Rui saiu da casa do amigo que o acolhera após regressar a Portugal, não tinha onde ficar. Pedro, um indivíduo sem-abrigo que conheceu, informou-o do local onde pernoitava na rua, juntamente com outros indivíduos sem-abrigo, e convidou-o a ficar lá. Será lá que Rui permanecerá durante quatro anos, montando uma "tenda" improvisada com espaço para duas pessoas dormirem. Na ausência de uma casa, o local de pernoite na rua é da maior importância. Para quem vive na rua, a possibilidade de utilizar uma parte dela para dormir, comer ou conviver é fundamental para a sobrevivência cotidiana. É aí que se pode tentar criar um mínimo de privacidade em espaço público; é o local de pernoite que possibilita uma tênue e precária reconstrução do 
self ao final do dia. Para além da materialidade do espaço, ter acesso a um local de pernoita tem uma dimensão de sociabilidade. Sendo partilhado com outros indivíduos, é ali que se podem desenvolver de modo privilegiado relações de camaradagem, de partilha, de apoio emocional. É também um ponto fixo na rotina diária de quem vive na rua, fornecendo um grau mínimo de segurança - física, mas, sobretudo, emocional e simbólica.

Chegar a esse espaço foi uma experiência ambígua para Rui. Lá conhecerá uma história longa de agressões e roubos. Mas, apesar destes problemas (significativos), o espaço de pernoite permite-nos observar também uma dimensão de reciprocidade, de solidariedade e de apoio entre "pares" - indivíduos que, com ou sem abrigo, têm posições estruturais similarmente dominadas e pobres. Lá desenvolvem-se relações entre estes atores e os laços criados fornecem um grau mínimo de proteção (partilha de bens, de comida, de dinheiro) e de reconhecimento pela compreensão das semelhanças das experiências de dominação. Tomar conhecimento do espaço de pernoite e obter a possibilidade de aí ficar apresenta as quatro formas que Lemieux (2000:48) afirma poderem assumir os fluxos de ajuda: informação, apoio emocional, material e camaradagem. Esta ajuda multidimensonal está presente quando Pedro propõe a Rui que este permaneça no local onde dorme. A informação indica um sentimento de solidariedade que, com a interação continuada, se traduz em apoio emocional e camaradagem recíprocas. Também a ajuda material está presente, ainda que marcada pela pobreza e precariedade. O espaço é em si mesmo materialidade, importante num contexto em que outras formas de apoio material estão indisponíveis ou estão disponíveis em níveis muito reduzidos - dinheiro, bens, habitação.

Segundo uma lógica de reciprocidade indireta, mesmo após a saída de Pedro do local, Rui continua a disponibilizar um colchão e proteção contra o frio a quem lhe peça para dormir junto dele por algumas noites. O único argumento que Rui concebe para proibir alguém de dormir dentro da tenda é o fato de já se encontrar lá alguém, dado que o espaço exíguo não lhe permite aceitar mais de uma pessoa de cada vez. Contudo, tendo em vista que considera que o espaço onde a tenda se encontra não é seu, é sempre possível dormir naquele local, desde que fora da tenda quando não há lá lugar para mais uma pessoa. Nestes casos, Rui empresta uma manta ou um cartão a quem dorme do lado de fora. 
$\mathrm{O}$ acesso ao espaço de pernoite permite-nos encontrar uma forma de dádiva contextualizada na rua. Há uma lógica de reciprocidade no dom materializado no acesso ao local, mas esta não é compreensível segundo a perspectiva mercantil. Não é reciprocidade direta e simétrica entre os envolvidos. Rui não dá fruto de um cálculo instrumental com o intuito de receber do sujeito a quem deu. Há reciprocidade, mas ela é indireta, difusa e diferida no tempo ${ }^{10}$. Rui dá, pois sente que recebeu quando necessitou - Pedro garantiu-lhe o acesso ao espaço de pernoite. Mas, sobretudo, dá porque về sua frente um ser humano que precisa de ajuda. $\mathrm{O}$ valor de elo deste dom é estabelecido não à escala dos dois envolvidos diretos, mas à escala do grupo mais amplo possível - a humanidade. É por via do sentimento de responsabilidade para com a humanidade em geral que o dom é realizado. Qualquer valor de elo mais restrito entre Rui e o donatário direto deriva da pertença comum à humanidade sentida entre ambos os envolvidos. Como Chabal (1996) defende, é a reciprocidade que funda a responsabilidade para com o outro, mas uma reciprocidade, no caso, estabelecida a uma escala que ultrapassa tanto o doador quanto o donatário, inserindo ambos na comunidade humana. O dom "puro" é impossível na medida em que for visto como desinteressado. Mas, se o interesse não for reduzido ao interesse instrumental, por si, constata-se que não há dom mais interessado do que o que é interessado pelo bem-estar do outro, do outro enquanto entidade simultaneamente concreta (o ser humano à minha frente, que necessita de ajuda) e abstrata (um membro da humanidade, não importa que membro em particular). Como Chabal afirma, "eu dou para que tu dês mas não forçosamente a mim. Não serás sequer talvez tu quem dará mas um outro que dará a um outro... Uma reciprocidade descontínua, aparentemente descontínua, reveladora de interações escondidas, é descoberta" (1996:139, ênfases no original).

Esta observação de uma reciprocidade indireta e o mais difusa possível no dom na vida na rua permite-nos olhar ainda para uma idiossincrasia desta relação de dádiva, que força a reavaliar a importância da confiança para o dom. Como foi visto, o valor de elo do dom necessita de confiança no outro, dado que só pela confiança se pode fundar e manter o laço. Do ponto de vista do utilitarismo, isto é extraordinárioainda que as evidências empíricas nos forcem a admitir que é também um estado normal das interações humanas. Mas, ao contrário do postulado pelos teóricos do dom (Godbout e Caillé, 1997; Caillé, 2000; Godbout, 2000), defendo que, olhando para a relação de dádiva no fe- 
nômeno dos sem-abrigo, é possível afirmar que a confiança não está sempre presente no dom, e que ela não é, porventura, o mais importante para manter a relação. Se pode ser visto como extraordinário que se dê-diriam os utilitaristas - "somente" com base na confiança, mais extraordinário ainda é dar-se em situação de absoluta desconfiança. $\mathrm{Na}$ rua, observam-se situações de dádiva em que o doador tem, com base na experiência da interação concreta e continuada com o donatário, consciência de que não pode, em situação alguma, confiar nele. Rui mais de uma vez permitiu que indivíduos que o roubaram permanecessem na tenda. Ao fazê-lo, não tem qualquer confiança no outro; tem a mais profunda desconfiança. Dá por se sentir responsável, não tanto para com o outro específico que necessita de ajuda, mas para com o outro abstrato, representante da humanidade. Se, quando precisou, recebeu (foi-lhe permitido ficar naquele espaço), então, sente como sua obrigação dar a quem necessita. E o faz sabendo que pode ser roubado pelo donatário passado pouco tempo. O que permite que a dádiva ocorra em situação de desconfiança é a esperança de que o outro cumpra a sua parte: que não o roube, num plano imediato; que, eventualmente, ajude outrem quando for preciso; que, ao mesmo tempo o ajude caso seja necessário ainda que isto seja secundário e não pensado de modo instrumental.

O caráter extraordinário da dádiva assente na confiança empalidece perante o desta dádiva fundada na esperança e na responsabilidade abstrata. Rui dá por se sentir na posse de uma responsabilidade insubstituível para com o outro, na qual o fato do outro cumprir a parte dele na relação é secundário perante o fato de eu cumprir a minha. Esperar que o outro cumpra e confiar que ele o faça são duas realidades substancialmente diferentes. A responsabilidade para com o próximo (o familiar, o amigo) pode surgir através da confiança recíproca, mas para com a humanidade apenas é concretizável com base na ideia de que eu tenho responsabilidades independentemente das do outro serem ou não cumpridas, in extremis, existam estas ou não. $\mathrm{O}$ fato do outro ser responsável na relação, responsável a meu respeito, não tem o mesmo peso da minha responsabilidade para com ele "porque sou responsável de uma responsabilidade total, que responde por todos os outros e por tudo o que é dos outros, mesmo pela sua responsabilidade. O eu tem sempre uma responsabilidade a mais do que todos os outros" (Lévinas e Nemo, 1988:91, ênfase no original) ${ }^{11}$. 


\section{DÁDIVA-CARIDADE: QUANDO 0 DOM DESQUALIFICA E 0 MERCADO E 0 ESTADO SÃO A SOLUÇÃO}

Em razão dos baixos rendimentos provenientes do RSI e pequenos trabalhos esporádicos na construção civil, Rui é forçado a recorrer frequentemente à caridade para sobreviver. Para obter comida, recorre ao apoio de diversas instituições que fornecem alimentos sem pedir retorno monetário a quem necessita. Mas, mesmo assim, é, por vezes, forçado a pedir esmola a transeuntes e a alguns conhecidos. Em todos os casos, estamos fora do âmbito da sociabilidade primária e também do mercado. Na lógica de Godbout (2000), estamos perante diversos tipos de dom aos estranhos que, para o autor, são idiossincráticos da modernidade ocidental. Dependendo da relação em causa, Rui torna-se donatário tanto como "estranho desconhecido" como quanto "estranho conhecido", quanto ainda como "estranho familiar" (Godbout, 2000:79 et passim). As relações do primeiro tipo - entre "estranhos desconhecidos" - são, talvez, as que menos influenciam negativamente a identidade de Rui. Pedir esmola é humilhante, desqualifica, mas Rui não utiliza a mendicidade como estratégia cotidiana, excetuando no que toca ao recebimento de comida. Não sendo uma estratégia frequente, Rui não se depara frequentemente com os "estranhos desconhecidos" que exerceram para consigo caridade, pelo que os sentimentos que esta relação pontual lhe possa despertar não estão sempre presentes.

O caso é diferente no tocante às relações com as instituições que trabalham com indivíduos sem-abrigo e outros sujeitos extremamente pobres. Nestas relações, estamos perante interações com "estranhos conhecidos" ou "estranhos familiares" mas também diante de relações oficiais estatais. O setor da "assistência" aos indivíduos sem-abrigo agrega tanto instituições do Estado quanto do Terceiro Setor (parceiras do Estado ou não; religiosas ou seculares). Como defende Feldman (2006), o fenômeno dos sem-abrigo é problemático não só em relação à escassez de recursos materiais, mas também à frequente negação de reconhecimento a que quem vive na rua é sujeito. O desrespeito pelos indivíduos desprovidos de poder, que Sennett (2004) afirma ter-se tornado habitual na contemporaneidade, é sentido por Rui nas suas interações com várias instituições. Na sua relação com os profissionais destas instituições, Rui sente-se constantemente desqualificado, e sente na pele toda a carga negativa associada ao rótulo de "sem-abrigo". Os seus atos de reivindicação de direitos, as suas exigências de que o tra- 
tem como cidadão, são frequentes. Funcionando no registro da sociabilidade secundária, o que está em causa é a substituição de um rótulo que exprime uma posição negativa - "sem-abrigo" - por outro, indicador de uma posição positiva - "cidadão". Os sentimentos de desqualificação e de desrespeito são particularmente fortes em Rui por sentir que é inserido numa relação de dádiva (caridade e não direito) em que não pode nunca cumprir as suas obrigações ${ }^{12}$. É precisamente isto que o desqualifica. Ao exigir ser tratado como "cidadão", procura retirar as relações "assistencialistas" da esfera da dádiva - em que nunca poderá reciprocar, nunca poderá ser doador - para colocá-las na esfera do Estado, onde a "assistência" que lhe prestam pode ser interpretada como uma questão de justiça. O problema fundamental é o fato de, mesmo na sua interação com o Estado, Rui não sentir que a relação se processa num registro de justiça e igualdade, mas num de dádiva sob a forma de caridade. Ao ser permanentemente desqualificado, remetido para a posição de um donatário incapaz de se tornar doador, e reificado como "recipiente de assistência", Rui encontra-se numa posição em que é impossível deixar de sentir que incorre numa dívida, e numa dívida que, pelas características contextuais que tem, é sentida por ele como inteiramente negativa e não recíproca. A dádiva, quando é realizada no registro caritativo da "assistência", seja o doador o Estado ou uma instituição não estatal, magoa o receptor. Do ponto de vista de Rui, a dívida é insuportável e ilegítima: sente que o que devia ser um direito seu é encarado pelos doadores como um "favor que lhe fazem", pelo que a única alternativa é exigir que a relação substitua o registro da dádiva pelo da justiça.

Mas, se há relações de dádiva que são problemáticas na rua pela dominação que criam, a saída em direção ao Estado nem sempre é percebida como a solução para o problema. Um exemplo claro disto é a relação que Rui mantém com um funcionário de uma instituição que costuma frequentar. Há anos que, todos os meses, este indivíduo empresta pequenas somas de dinheiro a Rui ( $5 €$, em geral). Quando recebe o RSI, Rui faz questão de devolver o empréstimo. Face aos montantes em causa, é difícil conceber que o credor encare a relação como um empréstimo; é mais plausível que a veja como uma dádiva. Mas o que é significativo é o fato de Rui fazer questão de pagar. A honestidade do pagamento daquilo que é contraído declaradamente como um empréstimo é relevante, mas não esgota a questão. Mesmo que Rui pague a dívida monetária mensalmente, uma parte fica sempre por saldar: a disponibilidade de conceder o "empréstimo". Isto Rui não pode saldar, dado 
que não tem recursos suficientes para reciprocar. Diante disto, o pagamento da quantia emprestada, ficando a relação na esfera da dádiva, desqualifica Rui em permanência, colocando-o sempre do lado do donatário sem possibilidade de vir a ser doador. Tal dívida, contraída para com um indivíduo que não é um próximo (não é família, não é um amigo), não pode ser sentida de modo positivo por Rui. Se a solução para a desqualificação institucional atrás discutida é a saída da dádiva para o Estado, aqui, o desejado é a substituição do dom pelo mercado. Ao ser caracterizado pela (teórica) liberdade de saída de relações não desejadas, o mercado funda-se na "liquidação imediata e permanente da dívida" (Godbout, 2000:152). Rui não tenta terminar a relação que tem com o indivíduo, mas procura retirá-la da dádiva. Recodificando a relação de dom como uma relação mercantil, é possível a Rui não se sentir inteiramente desqualificado por ela.

\section{CONCLUSÃO}

Toda a relação de dom tem de ser contextualizada e a sua compreensão só é possível olhando para os laços pelos quais os dons circulam. Como defendem Godbout e Caillé, "o dom não é bom nem mau em si, nem sempre é desejável. Tudo depende do contexto da relação que lhe dá um sentido" (1997:295). Na rua, como noutras figurações, encontramos relações de dom particulares, que, tendo uma dimensão de liberdade, são sujeitas a constrangimentos estruturais e circunstanciais específicos.

A chegada e a permanência na rua são explicáveis não só pela quantidade como pela qualidade das relações de dádiva em que os indivíduos sem-abrigo se inserem. Ou seja, não só a obtenção de recursos pela dádiva é insuficiente - como é a que ocorre pelo Estado ou pelo mercado - para impedir que os indivíduos se tornem sem-abrigo e, depois, para possibilitar a saída da rua, como os dons que existem têm características particulares, passíveis de gerar instabilidade e insegurança. É este o caso das relações de dádiva que Rui estabelece com familiares, caracterizadas pelo princípio de que "uma mão dá enquanto a outra retira", i.e., a dádiva existe, mas é revogável e marcada pelo conflito. Esta possibilidade do que é dado ser depois retirado explica-se, em parte, pela escassez de recursos disponíveis a todos os envolvidos nestas relações de dom. Esta situação de revogabilidade do dom não diminui a sua importância para os envolvidos nem a sua significação sociológica mas complexifica a relação de dádiva. O dom é feito, o apoio é 
oferecido, seja ele fruto de um sentimento de obrigação familiar, do prazer de dar, ou de um misto de ambos. Isto leva a que o donatário seja, efetivamente, ajudado, ainda que não a tempo indeterminado. Este caráter temporário do dom é o que causa dor, mal-estar para o donatário, em particular, pois a importância representacional da família não diminui com esta idiossincrasia da dádiva. Se a família tende a ser o lugar de base da dádiva nas sociedades modernas ocidentais, o espaço onde é praticada com mais intensidade e onde é aprendida (Mermet, 1991; Godbout e Charbonneau, 1993; Godbout e Caillé, 1997; Caillé, 2000; Godbout, 2000; Portugal, 2006, 2011), tal não se verifica no caso de Rui. Ao longo da sua vida, as relações de dádiva que estabeleceu com familiares foram tensas, conflituosas, por longos períodos inexistentes ou insignificantes - em particular desde que chegou à rua. A sensação de uma ajuda que é insuficiente é dolorosa, mas o é precisamente por ocorrer nas relações familiares, nas quais as expectativas são maiores no tocante ao apoio.

Mas se a dádiva é insuficiente, é também fundamental para a sobrevivência cotidiana na rua. Combater a dominação da vida na rua, na praxis, é impossível pelo mercado ou pelo Estado. Apenas a dádiva tem este potencial, possibilitando a partilha, a camaradagem, a circulação de bens escassos. É de realçar, todavia, um tipo de relação de dom específico que não se baseia na confiança para a criação e manutenção do laço pelo qual os bens e serviços circulam. Com base na história de vida de Rui, encontramos, na rua, um tipo de dom que parte da desconfiança e que a secundariza perante a responsabilidade sentida para com o outro, responsabilidade essa que surge como derivativa do sentimento de responsabilidade motivado pela pertença comum à humanidade. Esta relação de dádiva não se forja na confiança mas na esperança: dou não por confiar que o outro cumpra as suas obrigações na relação mas por esperar que ele o faça, sendo que o fato de ele o fazer ou não é secundário perante o fato de eu, que sou sujeito de uma responsabilidade insubstituível por outrem, cumprir com as minhas obrigações - em que entro de livre vontade.

Se este tipo de dádiva existe, o dom em geral não deve ser romantizado, tal como não o deve ser o fenômeno dos sem-abrigo. Viver na rua é, acima de qualquer outra coisa, dominação e injustiça extremas, e as relações de dom em que os indivíduos sem-abrigo se inserem muito contribuem para essa dominação e para essa injustiça. Isto é particularmente válido para o caso das relações de dom que assumem uma forma 
caritativa, levando a que o indivíduo sem-abrigo donatário seja reificado numa posição permanentemente desqualificada de "assistido", de donatário sem capacidade para se tornar doador, sem capacidade para cumprir com as obrigações em que sente incorrer pela relação de dom. Se, em um nível empírico concreto, o Estado e o mercado apenas desqualificam, levando a que a dádiva se apresente como a única possibilidade de combater essa desvalorização, o dom está longe de ser sempre uma relação ideal para quem vive na rua. Por esse motivo, como as relações de Rui com as instituições "assistencialistas" e com o indivíduo que lhe costuma emprestar dinheiro permitem observar, o bem-estar de quem vive na rua não é assegurado pela dádiva - antes, seria assegurado pela possibilidade de obter, no nível da sociabilidade secundária, uma posição estrutural que não desqualifique o sujeito. Quando as instituições do Estado e do Terceiro Setor prestam "assistência" segundo o registro do dom, tal é sentido como indigno, desejando-se transferir a relação para a esfera da justiça, onde a "assistência" é uma questão de direito - basicamente, o que se sente passível de crítica é um Estado que não se comporta como Estado mas como parceiro privilegiado numa relação de dádiva. De modo similar, quando as relações de dádiva criam obrigações não desejadas, como é caso dos empréstimos em que Rui incorre, o mercado é encarado como a esfera preferencial para desenvolver a relação, libertando o donatário de obrigações que não tem possibilidade de cumprir.

(Recebido para publicação em agosto de 2013)

(Reapresentado em novembro de 2013)

(Aprovado para publicação em dezembro de 2013) 


\section{NOTAS}

1. Mouvement Anti-Utilitariste dans les Sciences Sociales. Nas últimas décadas, este movimento intelectual tem desenvolvido um trabalho variado sobre o paradigma da dádiva, impulsionado, sobretudo, por Alain Caillé e Jacques Godbout. O nome do movimento deve ser entendido como tendo, em simultâneo, uma dimensão negativa - o antiutilitarismo - e uma positiva - a homenagem ao trabalho de Marcel Mauss, em particular, à sua obra mais conhecida, o Ensaio sobre a Dádiva (2008). Para uma breve história do M.A.U.S.S. e uma discussão destas duas acepções do seu nome, cf., por exemplo, Caillé (2010).

2. Encontramos diferentes (ainda que não antagônicas) e estimulantes interpretações da obra de Marcel Mauss em Caillé (2000:27-44), Godbout (2004), Graeber (2001) e Martins (2005).

3. Para Portugal (2006), o que tem propriedades "alquímicas" é o parentesco, i.e., é nos laços familiares, em particular, nos laços consanguíneos, que se encontra esta característica de tornar "equivalente" o que não o é. Concordando com a autora sobre a diferença fundamental entre as características dos laços familiares e as de todos os outros, parece-me, contudo, que o seu conceito pode ser ampliado. Pode haver uma tendência mais pronunciada para, fora do parentesco, procurar equivalência na dádiva, reconvertendo-a numa relação mercantil. Mas, fora do parentesco, o dom pode também ser "alquímico", dado que se assenta na manutenção da dívida. A equivalência pode ser buscada e até mesmo atingida, passando a relação para o modelo mercantil, mas, quando tal ocorre, a relação sai do princípio do dom para o do mercado. Enquanto a relação é regida pelo dom, ela tende a "encontrar equivalências" onde não as há, quanto mais não seja, pois os participantes na dádiva têm em conta as características pessoais dos donatários e doadores, valendo o que circula em função do local onde circula e dos sujeitos entre os quais circula. Tal não significa que todo o dom é "alquímico", mas, onde há dívida mútua positiva, há "alquimia", e há dívida mútua positiva fora da família.

4. Como nos mostram vários autores, em particular, desde Veblen (2009), o mercado não tem só valor de uso e de troca: as coisas têm valor simbólico e estatutário. Têm também valor de signo, como Baudrillard (1995) defendeu. Mas estas são perspectivas mercantis, ainda que ultrapassem largamente o mercado da troca contratualmente estabelecida. A perspectiva da dádiva avança noutra direção, olhando para o valor extramercantil das coisas.

5. Cf. Caillé (2006) para uma discussão sobre as variações dos termos (dés)intérêt e (dés)intéressement, palavras francesas dificilmente transponíveis para português e cujas traduções imperfeitas podem ser, respectivamente, "(des)interesse" e "(des)interessamento". Em linhas gerais, o primeiro termo remete para o interesse instrumental, pelo próprio, e o segundo para o interesse por outrem. Apesar de nos depararmos com um problema claro de tradução, a questão é mais vasta do que isso: a atual naturalização ontológica e sociológica de várias premissas da perspectiva utilitarista levam a que seja difícil (impossível?) conceber, dentro do modelo mercantil hegemônico, uma versão do interesse que não diga respeito ao próprio. Como consequência, ao afirmar que o dom é "interessado", a real significação desta afirmação perde-se, enfatizando-se somente uma das várias dimensões da dádiva - que não é possível negar em abstrato nem em geral - o interesse por si. Esta forma particular de 
entender o interesse leva a que a dádiva surja ora como egoísta, ora como altruísmo puro. Mas, se o altruísmo puro é somente a negação do egoísmo, este se revela impossível, impossibilitando também a existência da dádiva - a dádiva desinteressada não existe. O que esse argumento dominante torna invisível é o fato de nem todo o interesse ser interesse por si; de nem todo o interesse ser fruto de um cálculo racional instrumental: há interesse por outrem. Assim sendo, aceitar que a dádiva é sempre interessada não equivale a aceitar que toda a dádiva decorre de um interesse egoísta em busca de retribuição. Ver também Caillé (2000).

6. O Rendimento Social de Inserção foi instituído em Portugal em 2003, substituindo o Rendimento Mínimo Garantido, que vigorou desde 1996. Oficialmente, trata-se de uma prestação social estatal que procura garantir um rendimento mensal a sujeitos que não possuem outros rendimentos, visando combater situações de pobreza, mediante a assinatura de um contrato de inserção individual. Em 2014, tem um valor máximo de 178,15€ mensais, o que corresponde a 36,7\% do salário mínimo nacional (485€ mensais).

7. Todas as citações originalmente em idioma que não o português foram por mim traduzidas.

8. Cf. Aldeia (2011) para uma versão mais aprofundada desta história de vida.

9. Bourdieu (1995: 4 e ss.) atribui particular importância à dimensão temporal da dádiva, realçando que, para que a relação se mantenha, é necessário um diferimento temporal entre o dom e o contradom. Na ausência deste diferimento temporal, i.e., caso o donatário decida, no momento em que recebe, retribuir com um contradom imediato, a normatividade da dádiva, que, em situação normal, é ativamente não explicitada pelos envolvidos, torna-se inegavelmente explícita. No momento em que esta explicitação é realizada, a dimensão instrumental do dom é demonstrada em toda a sua intensidade, surgindo o contradom imediato como uma acusação do donatário ao doador: "o que me estás a dar é dado com o objetivo de me subordinar, pelo menos até ao momento em que surja uma retribuição". Deste modo, o contradom imediato consubstancia-se num insulto do contra-doador ao doador inicial, na medida em que o primeiro, rejeitando ficar subordinado ao segundo, rejeita as obrigações em que incorre pelo ato-relação de dom, passando a relação da normatividade da dádiva para a do mercado. Para que a relação de dom se mantenha, segundo Bourdieu, a existência de um período de tempo nem demasiado curto (que seria contradom imediato) nem demasiado longo (que seria dom nunca retribuído) é conditio sine qua non. Ou seja, a sequência de dom/contradom tem um tempo próprio que, caso não seja respeitado por um dos envolvidos, gera insulto, terminando a relação. Apesar do valor heurístico da reflexão bourdieusiana sobre a temporalidade do dom, a perspectiva do autor foca-se excessivamente no caráter instrumental dos atores em todos os seus atos. Vendo apenas a multiplicidade de estratégias contínuas pelas quais os atores envolvidos numa relação de dom procuram manter-se numa posição não dominada pelos outros envolvidos, este quadro conceitual não permite dar conta das dimensões não instrumentais das interações dos atores envolvidos numa relação de dádiva. Visto que as ações não calculadas (em rigor, não calculistas no sentido mercantil) são essenciais para que o dom possa ser compreendido, o quadro bourdieusiano é menos útil para compreender o dom do que a alternativa encabeçada pelo M.A.U.S.S. No caso empírico discutido, a dádiva é "exigida de volta" não pelos donatários, segundo um cálculo de custo-benefício, se sentirem prejudicados por Rui, 


\section{João Aldeia}

ou por se sentirem por ele insultados, uma vez que ele não retribui, mas antes devido a um conjunto de tensões interacionais decorrentes de uma copresença próxima e prolongada na mesma habitação. Ainda que estas tensões possam incluir decisões instrumentais e estratégicas, não se reduzem nunca a elas.

10. Cf. Chabal (1996) e Portugal (2006:563-564 et passim) para discussões mais amplas sobre os diferentes tipos de reciprocidade envolvidos no dom.

11. É importante não romantizar esta questão. Na vida de Rui, como em outras, existe também interesse estratégico por si próprio e cálculo instrumental. Mas, na vida de Rui como em outras, as estratégias calculadas (calculistas) estão longe de esgotar o que existe. Assim sendo, uma leitura utilitarista - mesmo dentro do quadro conceitual de Bourdieu (1995), sem dúvida um exemplar complexo e rico dentro desta corrente - conferiria uma forma "perversa" a este tipo particular de dom verificável na rua. A reciprocidade transformar-se-ia em reciprocidade direta (pelo menos em desejo de reciprocidade direta para benefício próprio), deixando de contemplar a possibilidade holística de uma reciprocidade indireta que motiva a ação de um sujeito que, concebendo-se a si mesmo e ao outro como representantes de uma mesma humanidade, se sente obrigado para com o outro sem que o outro aja explicitamente de modo a obrigá-lo e sem procurar, pelo dom que realiza, eliminar essa obrigação pela subordinação do donatário.

12. Sobre a dominação criada pelo dom que não pode ser retribuído, cf. Bourdieu (1995). Nas palavras do autor, "dar é também uma forma de possuir (um dom que não pode ser correspondido por um contra-dom cria um laço duradouro, restringindo a liberdade do devedor e forçando-o a adotar uma atitude pacífica, cooperante, prudente); (...) na ausência de qualquer garantia jurídica, ou de qualquer força coerciva, um dos poucos modos de "aprisionar" alguém é manter uma relação assimétrica duradoura tal como o endividamento" (idem:195). 


\section{REFERÊNCIAS BIBLIOGRÁFICAS}

ALDEIA, João. (2011), A Barraca do Rui. Os Laços Sociais no Fenómeno dos Sem-abrigo. Dissertação de Mestrado em Sociologia, Faculdade de Economia, Universidade de Coimbra, Coimbra.

BAUDRILlARD, Jean. (1995), Para uma Crítica da Economia Política do Signo. Lisboa, Edições 70.

BOURDIEU, Pierre. (1995), Outline of a Theory of Practice. Cambridge, Cambridge University Press.

CAILLÉ, Alain. (2000), Anthropologie du Don: Le Tiers Paradigme. Paris, Desclée de Brouwer.

(2006), “O Dom entre Interesse e Desinteressamento", in P. H. Martins e R. B. C. Campos (orgs.), Polifonia do Dom. Recife, Editora Universitária da UFPE, pp. 25-66.

. (2010), “Ouverture Maussienne”. Revue du MAUSS, no 36, pp. 25-33.

CHABAL, Mireille. (1996), “Quand la Réciprocité Semble non Réciproque... ou la Réciprocité Cachée". Revue du MAUSS, no 8, pp. 132-141.

DAMON, Julian. (2008), La Question SDF: Critique d'une Action Publique. Paris, PUF.

FELDMAN, Leonard C. (2006), Citizens Without Shelter: Homelessness, Democracy, and Political Exclusion. Ithaca/London, Cornell University Press.

GODBOUT, Jacques. (1996), “Les Bonnes Raisons de Donner”. Revue du MAUSS, no 8, pp. 167-178.

(2000), Le Don, la Dette et l'Identité: Homo Donator versus Homo Oeconomicus. Paris, La Découverte.

(2004), “L'Actualité de 1'“Essai sur le Don'”. Sociologie et Sociétés, vol. 36, no 2, pp. $177-188$

GODBOUT, Jacques e CAILLÉ, Alain. (1997), O Espírito da Dádiva. Lisboa, Instituto Piaget.

GODBOUT, Jacques e CHARBONNEAU, Johanne. (1993), "La Dette Positive dans le Lien Familial". Revue du MAUSS, no 1, pp. 235-256.

GOWAN, Teresa. (2010), Hobos, Hustlers, and Backsliders: Homeless in San Francisco. Minneapolis/London, University of Minnesota Press.

GRAEBER, David. (2001), "Marcel Mauss Revisited", in Toward an Anthropological Theory of Value. The False Coin of Our Own Dreams. New York, Palgrave, pp. 151-228.

LEMIEUX, Vincent. (2000), À quoi Servent les Réseaux Sociaux? Québec, Les Éditions de L'Irqc.

LÉVINAS, Emmanuel e NEMO, Philippe. (1988), Ética e Infinito. Lisboa, Edições 70.

LYON-CALLO, Vincent. (2008), Inequality, Poverty, and Neoliberal Governance: Activist Ethnography in the Homeless Sheltering Industry. Toronto, University of Toronto Press.

MARTINS, Paulo Henrique. (2005), “A Sociologia de Marcel Mauss: Dádiva, Simbolismo e Associação". Revista Crítica de Ciências Sociais, no 73, pp. 45-66.

MAUSS, Marcel. (2008), Ensaio sobre a Dádiva: Forma e Razão da Troca nas Sociedades Arcaicas. Lisboa, Edições 70. 


\section{João Aldeia}

MERMET, Jean-Claude. (1991), “Le Lien de Famille: La Réciprocité en Défaut”. Revue du MAUSS, no 12, pp. 137-146.

PAIS, José Machado. (2003), Ganchos, Tachos e Biscates: Jovens, Trabalho e Futuro. Porto, Âmbar.

PORTUGAL, Sílvia. (2006), Novas Famílias, Modos Antigos: As Redes Sociais na Produção de Bem-Estar. Tese de Doutoramento em Sociologia, Faculdade de Economia, Universidade de Coimbra, Coimbra.

. (2011), “Dádiva, Família e Redes Sociais”, in S. Portugal e P. H. Martins (orgs.), Cidadania, Políticas Públicas e Redes Sociais. Coimbra, Imprensa da Universidade de Coimbra, pp. 39-53.

RULLAC, Stéphane. (2005), Et si les SDF n'Étaient pas des Exclus? Essai Ethnologique pour une Définition Positive. Paris, L'Harmattan.

SENNETT, Richard. (2004), Respect in a World of Inequality. New York/London, W. W. Norton \& Company.

SNOW, David e ANDERSON, Leon. (1993), Down on their Luck: A Study of Homeless Street People. Berkeley, University of California Press.

VEBLEN, Thorstein. (2009), The Theory of the Leisure Class. Oxford/New York, Oxford University Press.

ZENEIDI-HENRY, Djemila. (2002), Les SDF et la Ville: Géographie du Savoir-Survivre. Paris, Bréal.

\section{ABSTRACT}

Beyond the State and Market: The Role of the Gift in Homelessness

Reflections on homelessness tend to reproduce the absences identified by the gift paradigm in Western societies modern thought. The state and the market are repeatedly perceived as the only spheres of social regulation and they are interpreted as the loci from which derive the structural causes and possible solutions for homelessness. This does not allow a complete understanding of the question or a consistent reflection on ways of minimizing the injustices of living on the streets. Thinking homelessness through the gift paradigm is relevant to the extent that it enables us to identify the usual invisibility of unofficial interpersonal relations that characterize life on the streets, allowing these interactions to be revalued in the discussion on homelessness.

Key words: gift; homelessness; social ties 


\section{RÉSUMÉ}

Au-delà de l'État et du Marché: Le Don dans le Phénomène des Sans-Abri

Les réflexions sur le phénomène des sans-abri ont tendance à reproduire les absences que le paradigme du don identifie dans la pensée sur les sociétés modernes occidentales. Habituellement, l'État et le marché sont vus comme les seules sphères de la régulation sociale, interprétés comme des lieux d'où proviennent les causes structurelles et les possibles solutions à ce phénomène, ce qui ne permet ni une compréhension complète de la question ni une réflexion soutenue sur les manières de réduire les injustices de la vie dans la rue. Penser le phénomène par le moyen du paradigme du don est important, car il nous permet d'identifier l'habituelle invisibilité des relations interpersonnelles non-officielles qui marquent la vie dans la rue, ce qui rend possible une remise en valeur de ces interactions dans la discussion du phénomène des sans-abri.

Mots-clés: don; sans-abri; liens sociaux

\section{RESUMEN}

Más allá del Estado y del Mercado: El Don en el Fenómeno de los Sin Techo

Las reflexiones sobre el fenómeno de los sin techo tienden a reproducir las ausencias que el paradigma del don identifica en el pensamiento sobre las sociedades modernas occidentales. Recurrentemente, se considera al Estado y al mercado como las únicas esferas de regulación social y se los interpreta como los espacios de donde derivan las causas estructurales y las posibles soluciones para el fenómeno. Ello no permite una comprensión completa del tema y tampoco una reflexión consistente sobre los modos de minimizar las injusticias de la vida en la calle. Pensar sobre el fenómeno por medio del paradigma del don es relevante porque permite identificar la habitual invisibilización de las relaciones interpersonales no oficiales que caracterizan la vida en la calle, posibilitando, a su vez, la revalorización de estas interacciones en el debate sobre el fenómeno de los sin techo.

Palabras clave: don; sin techo; lazos sociales 
